Psychotherapy and Psychosomatics

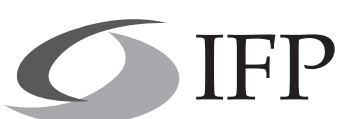

international federation for psychotherapy
Psychother Psychosom 2014;83:196

DOI: $10.1159 / 000358073$
Published online: April 17, 2014

\title{
IFP News
}

The IFP board is glad to write a brief sum-up of our latest 'Newsletter', which can be read in full at http://www.ifp.name/newsletter.htm.

The latest issue is devoted to the discussion related to the new Mental Health Law of the People's Republic of China, a big step forward for the provision of psychotherapy in this dynamic country. Kaiwen Xu and Xudong Zhao illustrated the great advantages of the new Mental Health Law of the People's Republic of China, which took effect on May 1, 2013. For example, one of the highlights is that the human right of the patients suffering from mental disorders is legally emphasized and protected. Another great progress is that psychotherapy and psychological counseling are defined as lawful professional mental health services, which is a historical milestone in China where psychology had not been seen as a branch of sciences until 1978. It is regrettable though that the law does not give psychologists the status they should have in view of their competent and absolutely necessary contribution in other countries such as the USA (where psychiatrists have generally a very limited interest in psychotherapy) or Germany, where most psychotherapy is delivered by psychologists, not to speak of the fact that most psychotherapy research is done by psychologists.

This issue also reports on the extraordinary experience in the UK of revising the delivery of psychotherapy as part of their National Health Service system. Prof. Chris Evans and Dr. Jo-Anne Carlyle comment on the recent government initiatives taken to increase the availability of psychological therapies to people experiencing mental health problems. Although they approve the growing willingness to use state funding to support provision of psychological therapies for people with mental health problems, they argue that serious problems stem from government overvaluing the results of randomized clinical trials (RCT) as the only credible evidence of effectiveness and from falsely equating absence of RCT-based evidence with evidence of absence of therapeutic value.

In addition, you will find an obituary for Prof. Didi Bachtiar Lubis. His death is a big loss, especially for his prominent and unceasing contributions to the whole society of Indonesian psychiatrists, especially in teaching and developing practices of psychotherapy.

A laudatio to our Board Member David Orlinsky, Professor emeritus of Human Development at the University of Chicago, is included marking his receipt of the new 2013 Society for Psychotherapy Research Lifetime Contribution Award. David Orlinsky is definitely one of the long-time leaders in modern psychotherapy research noted not only for his objective contributions but also for his great humanity and gentleness of spirit. The award is well deserved and we are proud to have him on board!

Finally, we announce the 2014 IFP congress in Shanghai with a specific theme and dates. We are glad that the Asian Pacific Association for Psychotherapy (APAP), member of IFP, will be a co-organizer of the conference. Please save the conference dates! Shanghai is a thrilling city and we look forward to seeing you there!

The IFP board wishes all of you a pleasant reading,

Fiammetta Cosci, IFP Newsletter Editor

\section{KARGER}

E-Mail karger@karger.com www.karger.com/pps
C 2014 S. Karger AG, Base

0033-3190/14/0833-0196\$39.50/0 